Article

\title{
Tramesan Elicits Durum Wheat Defense against the Septoria Disease Complex
}

\author{
Valeria Scala ${ }^{1}\left(\mathbb{D}\right.$, Chiara Pietricola $^{2}$, Valentina Farina ${ }^{2}$, Marzia Beccaccioli ${ }^{2}{ }^{\circledR}$, Slaven Zjalic ${ }^{3}$, \\ Fabrizio Quaranta ${ }^{4}$, Mauro Fornara ${ }^{4}$, Marco Zaccaria ${ }^{5}$, Babak Momeni ${ }^{5}$ (D, \\ Massimo Reverberi ${ }^{2, *(D)}$ and Angela Iori ${ }^{4}$ \\ 1 Consiglio per la Ricerca in Agricoltura e l'Analisi dell'Economia Agraria, Centro di Ricerca Difesa \\ e Certificazione, Via C.G. Bertero, 22, 00156 Roma, Italy; valeria.scala@crea.gov.it \\ 2 Università Sapienza, Dip. Biologia Ambientale, P.le Aldo Moro 5, 00185 Roma, Italy; \\ chiara.pietricola@live.it (C.P.); valentina.farifari@gmail.com (V.F.); marzia.beccaccioli@uniroma1.it (M.B.) \\ 3 Department of Ecology, Agronomy and Aquaculture, University of Zadar, Ulica Mihovila Pavlinovića bb, \\ 23000 ZADAR, Croatia; szjalic@unizd.hr \\ 4 Consiglio per la Ricerca in Agricoltura e l'Analisi dell'Economia Agraria, \\ Centro di ricerca Ingegneria e Trasformazioni agroalimentari, Via Manziana 30, 00189 Roma, Italy; \\ fabrizio.quaranta@crea.gov.it (F.Q.); mauro.fornara@crea.gov.it (M.F.); angela.iori@crea.gov.it (A.I.) \\ 5 Department of Biology, Boston College, Chestnut Hill, MA 02467, USA; zaccarim@bc.edu (M.Z.); \\ momeni@bc.edu (B.M.) \\ * Correspondence: massimo.reverberi@uniroma1.it
}

Received: 24 January 2020; Accepted: 8 April 2020; Published: 14 April 2020

\begin{abstract}
The Septoria Leaf Blotch Complex (SLBC), caused by the two ascomycetes Zymoseptoria tritici and Parastagonospora nodorum, can reduce wheat global yearly yield by up to $50 \%$. In the last decade, SLBC incidence has increased in Italy; notably, durum wheat has proven to be more susceptible than common wheat. Field fungicide treatment can efficiently control these pathogens, but it leads to the emergence of resistant strains and adversely affects human and animal health and the environment. Our previous studies indicated that active compounds produced by Trametes versicolor can restrict the growth of mycotoxigenic fungi and the biosynthesis of their secondary metabolites (e.g., mycotoxins). Specifically, we identified Tramesan: a $23 \mathrm{kDa} \alpha$-heteropolysaccharide secreted by T. versicolor that acts as a pro-antioxidant molecule in animal cells, fungi, and plants. Foliar-spray of Tramesan $(3.3 \mu \mathrm{M})$ on SLBC-susceptible durum wheat cultivars, before inoculation of causal agents of Stagonospora Nodorum Blotch (SNB) and Septoria Tritici Blotch (STB), significantly decreased disease incidence both in controlled conditions (SNB: $-99 \%$, STB: $-75 \%$ ) and field assays (SNB: $-25 \%$, STB: $-30 \%$ ). We conducted these tests were conducted under controlled conditions as well as in field. We showed that Tramesan increased the levels of jasmonic acid (JA), a plant defense-related hormone. Tramesan also increased the early expression (24 hours after inoculation-hai) of plant defense genes such as PR4 for SNB infected plants, and RBOH, PR1, and PR9 for STB infected plants. These results suggest that Tramesan protects wheat by eliciting plant defenses, since it has no direct fungicidal activity. In field experiments, the yield of durum wheat plants treated with Tramesan was similar to that of healthy untreated plots. These results encourage the use of Tramesan to protect durum wheat against SLBC.
\end{abstract}

Keywords: biostimulant; plant defense; mushrooms; antioxidant; Septoria disease complex; wheat

\section{Introduction}

Wheat is the main source of plant proteins in human diet. Plant diseases such as rusts, head blight, powdery mildew, and leaf blotch negatively affect wheat yield. Leaf blotch is caused by fungal 
pathogens, including Parastagonospora nodorum and Zymoseptoria tritici [1,2], and can significantly damage the global food security [3]. Septoria Leaf Blotch Complex (SLBC), one of the main diseases of wheat, may cause up to 50\% crop loss in years of severe epidemics [4].

Parastagonospora nodorum is a necrotrophic pathogen of both common and durum wheat. It causes necrotic leaf spots and thus hampers photosynthesis. To infect the plant, P. nodorum produces several necrotrophic effectors; Tox1, Tox3, and ToxA are small secreted proteins that alter or suppress the host immune response [5]. These effectors interact in a reverse manner with respect to the "gene-for-gene" model, with corresponding sensitivity loci in wheat [6,7]. Zymoseptoria tritici is a hemibiotroph—parasitic in living tissue and persistent in dead tissue - that commonly undergoes sexual reproduction; local populations are extremely variable and can rapidly adapt to fungicides [8]. By causing leaf necrosis, $Z$. tritici reduces the grain-filling potential of wheat and, as a consequence, yield.

Recently, the molecular basis of the interaction of wheat (specifically common wheat) with SLBC has been under the spotlight $[9,10]$. P. nodorum and Z. tritici infections account for approximately $70 \%$ of annual cereal fungicide ( $>€ 400$ million) usage in the European Union (EU) [3]. To counter these pathogens, chemical fungicides such as strobilurins, triazoles, and imidazoles are widely used; however, resistant fungal strains have been emerging [11]. The European regulation 128/2009 governing the use of pesticides [12] has recently removed several fungicides from the market to contain the environmental and health-related issues. At present, the employment of non-synthetic (natural) compounds in agriculture is increasing worldwide [13]: e.g., volatile molecules ((2,6-dichloroisonicotinic acid (INA), benzothiadiazole $(\mathrm{BTH})$ commercialized as $\left.\mathrm{BION}^{\circledR}\right)$; mineral nutrient and non-protein amino acids such as DL-3-amino-n-butanoic acid (BABA); cellular or molecular (Pathogen/Microbe/Damage Associated Molecular Patterns) PAMP, MAMP, or DAMP [14]. The mechanism behind resistance is presumably based on the induction of the host innate immune response. These responses are associated with the direct induction of antimicrobial proteins [15] via systemic acquired resistance, induced systemic resistance (ISR), and mycorrhiza-induced resistance. At the same time, a direct induction is not the only way to enhance plant defense. Defense priming is a viable approach to "boosted responses against pathogens" induced at a systemic level [16]. Since adaptive plasticity prevents an immune response in the absence of a challenge [16], defense priming allows the immune system to respond to stimuli with little energy expenditure. Defense priming responses are highly effective [17] and challenge-specific [18]. Plants can be "primed" with select elicitors to counter future attacks more efficiently than non-primed plants [19].

In this study, we explore the ability of purified Tramesan, a $23 \mathrm{kDa} \alpha$-heteropolysaccaride secreted by the basidiomycete Trametes versicolor [20], to act as an elicitor of durum wheat defenses for SLBC. Tramesan has demonstrated biological activity on fungal, plant, and animal cells $[19,20]$. Tramesan appears to act as a pro-antioxidant by inducing the expression of oxidative stress response-related genes, thus triggering a biological response. In Aspergillus flavus, a mycotoxigenic fungus, the presence of Tramesan strongly inhibits aflatoxin biosynthesis, without significantly influencing fungal growth. Aflatoxin biosynthesis is a response to oxidative stress in fungal cells [21]. The presence of Tramesan enhances the expression of Afyap $A$, an oxidative stress-related transcriptional factor, thus maintaining oxidant/antioxidant balance and downregulating aflatoxin synthesis. Similarly, Tramesan enhances the antioxidant response in wheat leaf cells providing better resistance to some fungal pathogens [19]. In murine melanoma cell lines, in which intrinsic oxidative stress boosts cell division, the presence of Tramesan resulted in reduction of cell growth and enhanced production of melanin [22].

In light of the data presented this work, we propose that Tramesan significantly reduces SBLC severity by eliciting durum wheat innate defense. 


\section{Materials and Methods}

\subsection{Preparation of Fungal Inoculum}

The fungal pathogen Parastagonospora nodorum, strain 15465, was isolated at the Council for Agricultural Research and Economics-Research Centre for Engineering and Agro-Food processing, CREA-IT, and submitted to the Culture Collection Agri-Food Important Toxigenic Fungi-Item, Institute of Science of Food Production (ISPA), National Research Council (CNR), Bari, Italy [23]. The fungus, stored at $-20^{\circ} \mathrm{C}$, was revitalized by transferring it into fresh potato dextrose agar plates $(41 \mathrm{~g} / \mathrm{L}$ PDA, HiMedia, Mumbai, India) and incubated at $20^{\circ} \mathrm{C}$ with a photoperiod of $12 \mathrm{~h}$ over 10 days. After growth, conidia were transferred with sterile needles to PDA Petri dishes and placed in a growth cabinet under the same temperature and light conditions. After incubation, sterile distilled water was added to each plate and the spores were gently scraped with special glass rods. The obtained spore suspension was filtered with a sterile gauze and diluted to a concentration of $10^{6}$ spores/mL [24]. Tween 20 surfactant was added to the suspension $(0.1 \% \mathrm{v} / \mathrm{v})$ to increase the adhesion to leaves.

Zymoseptoria tritici, strain 18258 was isolated from durum wheat at CREA-IT. To test its virulence, wheat cultivars (durum wheat: Svevo and Duilio cvs; bread wheat: Salamandra cv) were inoculated with $\mathrm{Zt} 18258$ in a greenhouse environment [25]. After 4 days, leaf segments from seedlings were cut and put on agar in Petri dishes at $20^{\circ} \mathrm{C}$ for subsequent culture and monoconidial isolation, identification, and storage. Three weeks later, a high presence of pycnidia was observed. The Zt strain was pathogenic to both wheat species. It was revitalized by transferring it to fresh PDA medium (potato dextrose agar, $39 \mathrm{~g} / \mathrm{L}$ HiMedia, Mumbai, India) and incubated at $18{ }^{\circ} \mathrm{C}$ with a photoperiod of $12 \mathrm{~h}$ over 10 days. After incubation, sterile distilled water was added to each plate and spores were scraped gently with special glass rods. The spores were then transferred to yeast-sucrose liquid medium (yeast extract $10 \mathrm{~g} / \mathrm{L}$; sucrose $10 \mathrm{~g} / \mathrm{L}$ ) and left shaking for 7 days at $18^{\circ} \mathrm{C}$, with permanent light. The spores were collected by centrifugation at $5000 \mathrm{rpm}$ for $5 \mathrm{~min}$ at $15^{\circ} \mathrm{C}$, washed twice with sterile distilled water, and resuspended in a $\mathrm{MgSO}_{4}$ solution $(0,01 \mathrm{M})$, containing Tween 20 surfactant $(0.1 \% \mathrm{v} / \mathrm{v})$. The concentration was adjusted to $10^{7}$ spores $/ \mathrm{mL}$.

\subsection{Tramesan Preparation}

Trametes versicolor, strain C, [26] is regularly maintained on potato dextrose agar (PDA, Difco) at $4{ }^{\circ} \mathrm{C}$, and renewed every 60 days at the collection of the Rome Botanical Garden. T. versicolor was grown for 7 days on PDA in Petri dishes at $25^{\circ} \mathrm{C}$. After 7 days, 3 plugs of $1 \mathrm{~cm}$ diameter, with uniformly grown biomass (mycelium + medium), were collected and added, under sterile conditions, to $100 \mathrm{~mL}$ of potato dextrose broth (PDB) and agitated at $150 \mathrm{rpm}$, at $25^{\circ} \mathrm{C}$, over 14 days. The entire mass (liquid medium + mycelium) was then homogenized using a Waring blender (speed 5 for 3 pulses of 2 min each) and added at 5\% v/v to PDB medium and grown over 14 days. Tramesan was purified as described by [20], then $2.3 \mathrm{~g}$ of lyophilized Tramesan were dissolved in $1 \mathrm{~L}$ of distilled sterile water. This solution was used to spray wheat plants in a greenhouse environment. Plants were treated with Tramesan at $3.3 \mu \mathrm{M}$ as previously described [20]. Tramesan was formulated with $0.1 \% \mathrm{v} / \mathrm{v}$ of Tween 20 as surfactant to increase its adhesion to leaves.

\subsection{Trials in Phytotron}

Kernels of two Italian commercial varieties of durum wheat (Svevo and Duilio; Syngenta Italia and SIS Società Italiana Sementi, respectively, T. turgidum subsp. durum (Desf. Husn.) moderately susceptible to SLBC, were superficially disinfected with a sodium hypochlorite solution $(0.1 \% \mathrm{v} / \mathrm{v}$, 10 minutes agitation) and washed three times with sterile distilled water. The disinfected seeds were placed in Petri dishes containing water/agarose $(2 \% \mathrm{w} / \mathrm{v})$ and incubated for $24 \mathrm{~h}$ at $20^{\circ} \mathrm{C}$, followed by $24 \mathrm{~h}$ at $4{ }^{\circ} \mathrm{C}$, and finally $48 \mathrm{~h}$ at $20^{\circ} \mathrm{C}$ for germination. The kernels were transferred in a twice autoclaved $\left(20 \mathrm{~min}\right.$ at $\left.121^{\circ} \mathrm{C}\right)$ soil mixture $(20 \mathrm{~L}$ of soil $/ 5 \mathrm{~L}$ of perlite), in pots of $0.5 \mathrm{~L}$. In a phytotron, temperature, humidity, and light were regulated to $20^{\circ} \mathrm{C}, 80 \%$ humidity, and $18 \mathrm{~h}$ light exposure with $150 \mu \mathrm{mol}$ of 
photon $\mathrm{m}^{-2} \mathrm{~s}^{-1}$ from 6 am to $10 \mathrm{pm}$. The pots were positioned on a rotary floor, so that different plants were subject to the same conditions. Plants ( $n=48 ; 24$ var. Svevo, 24 var. Duilio for each experimental condition) were irrigated three times a week. Four different experimental conditions were used: (1) plants non-inoculated and non-treated with Tramesan (Mock); (2) plants treated with Tramesan (T); (3) plants inoculated with P. nodorum ST15465 or Z. tritici ST18258 (Inf); (4) plants treated and inoculated with P. nodorum ST15465 or Z. tritici ST18258 (T + Inf). Tramesan (100 mL per 64 pots; $3.3 \mu \mathrm{M})$ was sprayed on seedlings of the 2 varieties at the 2-3 leaf stage (second leaf fully expanded), $48 \mathrm{~h}$ prior to pathogen inoculation. The inoculation of wheat plants with foliar pathogens was carried out by spraying conidial suspensions (P. nodorum: $10^{6}$ spores $/ \mathrm{mL}$; Z. tritici: $10^{7}$ spores $/ \mathrm{mL}$ ) containing Tween 20 surfactant $(0.1 \% \mathrm{v} / \mathrm{v})$ as previously described [24]. The inoculated plants were covered with black plastic sheets for $24 \mathrm{~h}$ and with transparent plastic sheets in the subsequent $24 \mathrm{~h}$, providing a humid saturated atmosphere necessary for spore germination and penetration into the leaves. Trials were conducted on a 9-day observation period. To assess Stagonospora Nodorum Blotch (SNB) or Septoria Tritici Blotch (STB) symptoms, a severity index (numerical rating from 1 to 5 ) was adopted following Liu's scale [27], where 0 represents absence of symptoms and 5 indicates large coalescent lesions. Results from this scale were then transformed into percentage of lesioned area (as reported by Liu) using the arc sen $\sqrt{ }(x)$ formula. To study the early effect of Tramesan on infected wheat, the seedling leaves were collected for subsequent analysis from $-48 \mathrm{~h}$ to 9 days after infection (dai).

\subsection{In-field Artificial Infection Trials}

Field trials in the growing season 2014-2015 were performed in Montelibretti (CREA-IT) and in Rome using durum wheat variety Svevo and the same strains of P. nodorum ST15465 and Z. tritici ST18258 used for artificial inoculations (see Section 2.3). In the crop season 2014-2015, we have 12 plots in two different fields located in Rome (latitude 41.969277; longitud 12.464256; m.a.s.1. 20) and in Montelibretti (RM) (latitude 42.129287; longitude 12.63969; m.a.s.1. 25) at the CREA-Research Centre for Engineering and Agro-Food Processing, CREA-IT. The Svevo wheat variety was sown (viable seeds: $\left.450 / \mathrm{m}^{2}\right)$ in plots of $1.5 \mathrm{~m} \times 2 \mathrm{~m}\left(3 \mathrm{~m}^{2}\right)$ using a randomized block design with three replicates. Different experimental conditions were set up (Table 1 ).

Table 1. Different experimental conditions used on durum wheat cultivars to study the effect of Tramesan on StagonosporaNodorumBlotch and SeptoriaTriticiBlotch in Montelibretti (Rome) and in Rome (Italy) field trials performed by the Council for Agricultural Research and Economics-Research Centre for Engineering and Agro-Food processing (CREA-IT) in the 2014-2015 growing season.

\begin{tabular}{|c|c|c|c|}
\hline Treatment & Application Time (GS) & Active Ingredient & Dose $\left(\mathrm{mL} / \mathrm{m}^{2}\right)$ \\
\hline Untreated control (non-inoculated and non-treated) & - & Water & 40 \\
\hline $\mathrm{T}$ & 47 & Tramesan & 40 \\
\hline Inoculated with P. nodorum ST15465 & 49 & Water & 40 \\
\hline T and inoculated with $P$. nodorum ST15465 & $47 ; 49$ & Tramesan & 40 \\
\hline Untreated control (non-inoculated and non-treated) & 37 & Water & 40 \\
\hline $\mathrm{T}$ & 37 & Tramesan & 40 \\
\hline Inoculated with Z. tritici ST18258 & 39 & Water & 40 \\
\hline T and inoculated with Z. tritici ST18258 & 37; GS 39 & Tramesan & 40 \\
\hline
\end{tabular}

Each plot in the two fields contained $n=250$ plants. The number of plants was fewer than the seeds, probably due to the considerable presence of birds at the time of sowing. The trials were performed in three plots per thesis (mock, T, Inf, T + Inf). Inoculation for the artificial contamination in the field plots was prepared as indicated in Section 2.1. As in Table 2, the plants were treated with Tramesan by spraying at the booting growth stage, GS 47, for SNB trials, and at stem elongation growth stage, GS 37, for STB trials. The inoculation of wheat plants with foliar pathogens was carried out by spraying conidial suspensions (P. nodorum: $10^{6}$ spores/mL at growth stage GS 49 ; Z. tritici: $10^{7}$ spores/mL at growth stage GS 39) containing Tween 20 surfactant ( $\left.0.1 \% \mathrm{v} / \mathrm{v}\right)$ as previously described [22]. The inoculated plots were covered with transparent plastic sheets for $48 \mathrm{~h}$, providing 
a humid, saturated atmosphere necessary for spore germination and penetration into the leaves. Over that plastic sheet, a plastic shade was used to protect the plants from direct sunlight. Infections were assessed by visual observations of symptoms, such as STB and SNB severity on the flag leaf at growth stage GS 83, according to Iori et al., 2015 [24]. In the field, diseases were assessed every 7 to 10 days until the ripening stages. All field trials were harvested at maturity.

\subsection{Calibration Curve of P. nodorum and Z. tritici and Quantification of Fungal DNA by Real-time PCR}

Total DNA was extracted from spores of P. nodorum ST15465 and of Z. tritici ST18258. The spores $\left(10^{8}\right)$ were collected by pipetting $50 \mu \mathrm{L}$ of Triton-X100 (Merck KGaA, Darmstadt, Germany) in Petri dishes $(9 \mathrm{~cm})$ completely covered with conidiating mycelia. Then, $500 \mu \mathrm{L}$ of cetyl trimethylammonium bromide (CTAB) buffer (1 M Tris at $\mathrm{pH} \mathrm{8,} 5 \mathrm{M} \mathrm{NaCl}, 0.5 \mathrm{M}$ EDTA, 2\% w/v CTAB) and glass beads (425-600 $\mu \mathrm{m}$; Sigma-Aldrich) were added to the spores/Triton-X100 mix in $2.0 \mathrm{~mL}$ tubes and DNA was extracted as previously described [24]. Real time PCR was performed in a LineGene K PCR detection system (Bioer, Hangzhou, China) with the following cycling conditions: $95^{\circ} \mathrm{C}$ for $10 \mathrm{~min}$, followed by 40 cycles of $95{ }^{\circ} \mathrm{C}$ for $15 \mathrm{~s}, 55{ }^{\circ} \mathrm{C}$ for $30 \mathrm{~s}$, and $72{ }^{\circ} \mathrm{C}$ for 1 min to amplify the $\beta$-tubulin gene (for_TGGGTACGCTTTTGATCTCC; rev_AACGAGGTGGTTCAGGTCAC) of Parastagonospora nodorum (acc. n. KF252679). Cycling of $95{ }^{\circ} \mathrm{C}$ for $10 \mathrm{~min}$, followed by 40 cycles of $95{ }^{\circ} \mathrm{C}$ for $15 \mathrm{~s}, 62{ }^{\circ} \mathrm{C}$ for $30 \mathrm{~s}$, and $72{ }^{\circ} \mathrm{C}$ for $1 \mathrm{~min}$ to amplify the GAPDH gene (for_TCCGTCGTTGACTTGACCTG; rev_TCTGAACTCAACGGTCGCTT) of Zymoseptoria tritici (acc. n. XM_003855615). Standard calibration was performed plotting the real-time PCR (RT-PCR) signals obtained for S. nodorum and Z. tritici genomic DNA extracted from fungal strains in the concentration range of $5 \mathrm{pg}$ to $50 \mathrm{ng}$. The equation describing the increase of DNA concentration was calculated $\left(\mathrm{y}=3 \times 10^{8} \mathrm{e}-0.6396 \mathrm{x}, \mathrm{R}^{2}=0.9967\right.$ for P. nodorum; $\mathrm{y}=2 \times 10^{6} \mathrm{e}-0.756 \mathrm{x}, \mathrm{R}^{2}=0.9864$ for Z. tritici) and used afterwards as a reference standard for the extrapolation of quantitative information for DNA targets of unknown concentrations. The efficiency of the PCR reaction (102\%) was obtained from the calibration curves slope $\left(E=10^{-1 / \text { slope }}-1\right)$. For quantifying the fungal amount within the plant tissues, total DNA was extracted from the wheat leaves ( $n=2$ leaves/plants; $n=196$ plants) at different times after pathogen inoculation (0-9 days after inoculation; dai) according to the Färber method with minor modifications [28]. RT-PCR (Bioer, Hangzhou, China) as indicated above used total DNA extracted from wheat leaves for PCR quantification of the amount of fungal DNA within plant tissues. RT-PCR amplification reactions were carried out in three technical replicates, and the results were expressed as ng of target DNA/ $\mu$ g of total DNA.

\subsection{Analysis of Expression of Plant Defense-related Genes}

For plant gene expression analysis, aliquots of $25 \mathrm{mg}$ of lyophilized wheat leaves sampled as indicated in [6] were ground in liquid nitrogen and treated for RNA extraction. RNA extraction was performed with the TRI reagent method (Sigma-Aldrich) according to manufacturer's instructions; cDNA was obtained using the first strand cDNA synthesis Super Script II RT-PCR kit (Thermo Fisher Scientific, Waltham, MA, USA). RT-PCR was performed as described [28]. To identify target genes and primer (Supplementary Table S1) homologs in wheat, we used the NCBI, DFCI Wheat Gene Index, an International Wheat Genome Sequencing Consortium chromosome survey sequence repository at Unité de Recherche Génomique Info INRA databases, and specific references (for the homologues of cerk1 see [29]; for the homologue of mpk3 see [30]). The $\beta$-tubulin gene of T. turgidum subsp. durum (acc. N. AJ971820.1; for 5'-GCTGCTGTATTGCAGTTGGC-3'; rev 5'-AAGGAATCCCTGCAGACCAG-3') was employed as a housekeeping reference to normalize the expression of the target genes in the wheat leaves. Previous trials showed that Tramesan was effective in limiting the growth of pathogens and in reducing the symptoms on leaves. Ruling out a direct antimycotic effect of Tramesan (M. Reverberi, unpublished results) on P. nodorum ST15465 and Z. tritici ST18258, we carried out experimental tests to evaluate whether this exo-polysaccharide was able to induce defense responses in wheat plants. In this regard we analyzed the expression of some marker genes of defense response in the durum 
wheat variety Svevo: the pathogenesis related $P R 1, P R 4, P R 9, C H I T 2$ (coding for a chitinase active against fungi), MCA2 (coding for a metacaspase), NADPH-ox (coding for the anion superoxide forming NADPH oxidase), PAL (coding for the phenylalanine-amonialyase), CERK1 (coding for the chitin related receptor CERK), and MPK3 (coding for the MAP kinase MPK3). Indeed, this variety was more susceptible to both pathogens.

The relative expression of wheat genes was calculated following the $2^{-\Delta \Delta \mathrm{Ct}}$ method using untreated samples as calibrators. RT-PCR was prepared in a $20 \mu \mathrm{L}$ reaction mixture containing SYBR green JumpStart Taq Ready Mix 1X (Sigma-Aldrich), $3 \mathrm{mM} \mathrm{MgCl}_{2}$, and $0.5 \mathrm{mM} \beta$-tubulin. RT-PCR was performed in a LineGene K PCR detection system (Bioer, Hangzhou, China). PR1, PR4, PR9, CHIT2, $M C A 2, N A D P H-o x, P A L, C E R K 1$, and MPK3 expressions were evaluated at inoculation time $\left(\mathrm{t}_{0}\right)$ and at 24 hours after inoculation (hai) on Svevo artificially infected with: (1) P. nodorum not treated (Inf Pn) or treated $(\operatorname{Tr}+\operatorname{Inf} P n)$ with $3.3 \mu \mathrm{M}$ of Tramesan or (2) Z. tritici not treated $(\operatorname{Inf} Z t)$ or treated $(\operatorname{Tr}+\operatorname{Inf} Z t)$ with $3.3 \mu \mathrm{M}$ of Tramesan.

\subsection{Plant Hormones Analysis}

Salicylic acid (SA) and jasmonic acid (JA) were sampled as indicated in Oliver et al., 2012 [6] and extracted from wheat leaves in all the experimental conditions described above. The quantification was done by the addition of the internal standard 1-naphthaleneacetic acid (NAA, MW $186.21 \mathrm{~g} \mathrm{~mol}^{-1}$ ), at $5 \mu \mathrm{M}$ final concentration. An amount of $30 \mathrm{mg}$ of lyophilized durum wheat leaves was ground with liquid nitrogen, mortar, and pestle. Hormones were extracted with $750 \mu \mathrm{L}$ of $\mathrm{MeOH}: \mathrm{H}_{2} \mathrm{O}: \mathrm{HOAc}$ (90:9:1, v/v/v), mixed, and centrifuged for $1 \mathrm{~min}$ at 10,000 rpm. The supernatant was collected, and the extraction was repeated. Pooled supernatants were dried under nitrogen gas flux. The dried samples were resuspended in $200 \mu \mathrm{L}$ of $0.05 \%$ HOAc in $\mathrm{H}_{2} \mathrm{O}$-acetonitrile $(85: 15, \mathrm{v} / \mathrm{v})$. The analysis of SA and JA was performed with a LC-MS/MS Agilent 6420. The acquisition was in MRM negative ion mode $[\mathrm{M}-\mathrm{H}]^{-}$. Chromatographic separation was performed with a Zorbax ECLIPSE XDB-C18 rapid resolution HT $4.6 \times 50 \mathrm{~mm} 1.8 \mu \mathrm{m}$ p.s. column (Agilent Technologies, Santa Clara, CA, USA) at room temperature, and the injected volume was $10 \mu \mathrm{L}$. The mobile phases consisted of $\mathrm{A}: \mathrm{H}_{2} \mathrm{O}$ containing $0.05 \%$ HOAc, and B: acetonitrile. The elution gradient was as follows: $0-3 \min 15 \% \mathrm{~B}, 3-5 \min 100 \% \mathrm{~B}$, 5-6 $\min 100 \%$ B, 6-7 $\min 15 \%$ B , 7-8 $\min 15 \%$ B. The gradient was followed by 5 min for re-equilibration. The flow rate was constant at $0.6 \mathrm{~mL} \cdot \mathrm{min}^{-1}$. The injector needle was washed with the mobile phase in the wash at the end of each HPLC run. Nitrogen was used as the nebulizing and desolvation gas. The temperature and flow of the drying gas were $350{ }^{\circ} \mathrm{C}$ and $10 \mathrm{~mL} \cdot \mathrm{min}^{-1}$, respectively, with a nebulization pressure of $20 \mathrm{psi}$. The capillary and cone voltage were $4000 \mathrm{~V}$. The main transition and qualifier ions were 137.2 $\rightarrow 92.9,137.2 \rightarrow 64.8$ for SA (CE 20, FV 135), 209.2 $\rightarrow 59.1,209.2 \rightarrow 41.3$ for JA (CE 28 FV 135), and $245 \rightarrow 180.8$ for the internal standard NAA (CE 16 and FV 100). To quantify hormone levels, a standard curve was generated for both compounds in the $0.01 \mu \mathrm{M}$ to $10 \mu \mathrm{M}$ range. Trend curves were linear within this range and the equations correlating relative (area) abundance and molarity were $y=3432.2 x, R^{2}=0.9973$ for $S A$ and $y=541.22 x, R^{2}=0.9813$ for JA, respectively.

\subsection{Statistics}

Data were analyzed by t-test, ANOVA and, in case of statistical significance, Fisher's multiple comparison tests between means were performed (XLSTAT, Addinsoft, Paris, France).

\section{Results}

\subsection{Phytotron Trials}

The SNB and STB severity on the leaves of two commercial varieties of durum wheat, Svevo and Duilio, was calculated based on Liu's scale, a 0-to-5 qualitative lesion-type rating scale that assesses symptoms on leaves at 7 dai (Table 2 and Figure 1). Phytotron trials were performed following the same 
timeline for both pathogens notwithstanding the fact that these are not the correct and proper ways to test pathogenicity of Z. tritici.

Table 2. Disease severity as measured at 7 dai at the second leaf stage according to Liu's scale (0-5) [23] in the durum wheat varieties (Svevo and Duilio) inoculated with P. nodorum ST15465 or Z. tritici ST18258. Mock: without Tramesan, non-inoculated. T: treated with Tramesan; $\mathrm{Tr}+$ Inf: treated with Tramesan, inoculated with the pathogen; Inf: inoculated with the pathogen. Fisher test on $n=48 \times 2$ biological repetitions.

\begin{tabular}{ccccc}
\hline & \multicolumn{4}{c}{ Durum Wheat } \\
\cline { 2 - 5 } & \multicolumn{2}{c}{ P. nodorum ST15465 } & \multicolumn{2}{c}{ Z. tritici ST18258 } \\
\cline { 2 - 5 } & Svevo & Duilio & Svevo & Duilio \\
\hline Mock & $0^{\mathrm{a}}$ & $0^{\mathrm{a}}$ & $0^{\mathrm{a}}$ & $0^{\mathrm{a}}$ \\
$\mathbf{T}$ & $0^{\mathrm{a}}$ & $0^{\mathrm{a}}$ & $0^{\mathrm{a}}$ & $0^{\mathrm{a}}$ \\
Tr + Inf & $1^{\mathrm{ab}}$ & $1^{\mathrm{ab}}$ & $0.7^{\mathrm{ab}}$ & $0.7^{\mathrm{b}}$ \\
Inf & $4^{\mathrm{b}}$ & $2^{\mathrm{b}}$ & $2^{\mathrm{b}}$ & $1.7^{\mathrm{b}}$ \\
F test $(\boldsymbol{p}$ value $)$ & $2.5 \times 10^{-5}$ & 0.031 & 0.0015 & 0.025 \\
\hline & $\mathrm{a}, \mathrm{b}$ & refer to Figure 1 upper and lower.
\end{tabular}

Results showed that plants treated with Tramesan had fewer symptoms compared to the untreated ones. Svevo was more susceptible to the disease (mainly P. nodorum) than Duilio. By quantifying the fungal DNA within leaf tissues at 0, 3, and 9 dai (Figure 1), we found that the pathogen load dramatically decreased under Tramesan treatment by up to $99 \%$ for $P$. nodorum, and up to $75 \%$ for Z. tritici.

\subsection{Field Trials}

The plants treated with Tramesan showed a lower severity of disease (Table 3; Supplementary Figure S1 and Table S2), even if results were less intense than those under controlled growth conditions (symptoms decreased by up to $25 \%$ for P. nodorum and up to $30 \%$ for Z. tritici). In addition, Tramesan treatment did not affect grain yields (5.29 $\pm 0.05 \mathrm{t} / \mathrm{ha})$ compared to untreated plots $(5.28 \pm 0.08 \mathrm{t} / \mathrm{ha})$ that only displayed limited SLBC leaf infection in our assay.

Table 3. SNB and STB severity on flag leaf (\%) in durum wheat (var. Svevo) at growth stage GS 83 grown in Montelibretti (Rome) and in Rome fields in the 2014-2015 growing season. Mock: without Tramesan, non-inoculated. T: treated with Tramesan; T + Inf: treated with Tramesan, inoculated with the pathogen (SNB: P. nodorum ST15465; STB: Z. tritici ST18258); Inf: inoculated with the pathogen. Values represent the mean $\pm \mathrm{SE}$ of three technical repetitions $(n=3)$.

\begin{tabular}{ccc}
\hline \multicolumn{2}{c}{ Svevo } \\
\hline & Severity on Flag Leaf (\%) SNB & Severity on Flag Leaf (\%) STB \\
\hline Mock & $3.2^{\mathrm{ab}}$ & $1.2^{\mathrm{a}}$ \\
$\mathbf{T}$ & $0.8^{\mathrm{a}}$ & $0.5^{\mathrm{a}}$ \\
Tr + Inf & $28.5^{\mathrm{b}}$ & $32.4^{\mathrm{b}}$ \\
Inf & $36.5^{\mathrm{c}}$ & $47.5^{\mathrm{c}}$ \\
F test $(\boldsymbol{p}$ value $)$ & $4.65 \times 10^{-4}$ & $1.73 \times 10^{-5}$ \\
\hline
\end{tabular}

Means followed by different letters are significantly different (the level of significance $p$ is shown in the table). $a, b, c$ refer to Figure 1 upper and lower.

\subsection{Expression of Defense Genes and Hormones in Durum Wheat Leaves}

Leaves were harvested at $48 \mathrm{~h}$ after treatment. RT-PCR showed a significant difference in gene expression in plants treated with Tramesan; notably, the enhancement of the expression of genes involved in the onset of plant defenses [19] occurred at $48 \mathrm{~h}$ after treatment compared to untreated 
plants. This significant difference of expression between Tramesan-treated and untreated plants was found in almost all the defense genes analyzed (Figure 2; Supplementary Table S3).
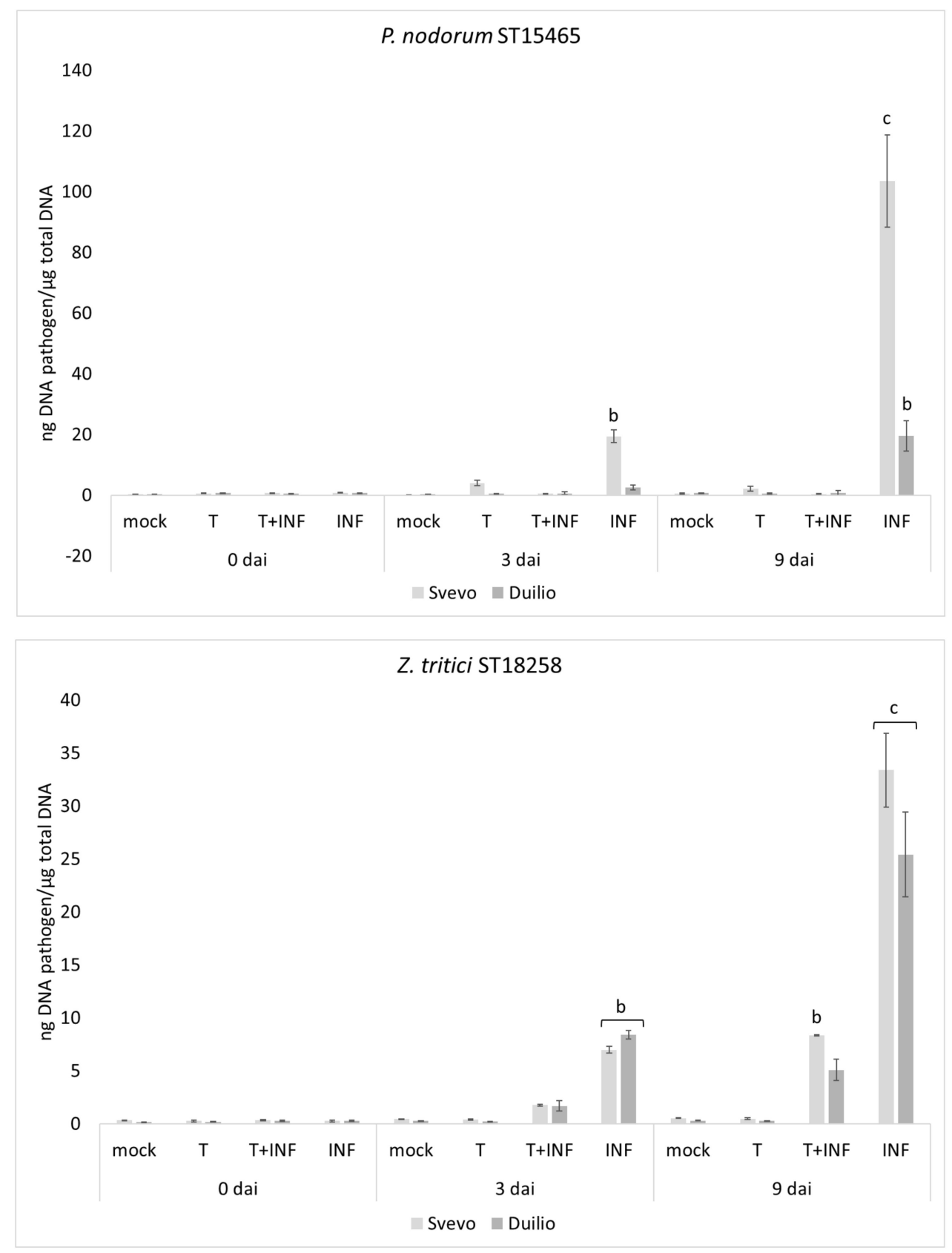

Figure 1. P. nodorum ST15465 (upper) and Z. tritici ST18258 (lower) growth assessed by qPCR. At 0, 3, and 9 days after inoculation (dai) in durum wheat (vars. Svevo and Duilio). Mock: without Tramesan, non-inoculated. T: treated with Tramesan; T + Inf: treated with Tramesan, inoculated with the pathogen; Inf: inoculated with the pathogen. Values represent the mean $\pm \mathrm{SE}$ as described in the methods section. Small capital letters in the chart represent the significantly different groups $(p<0.05$; Fisher's test).

The assay of SA and JA levels in infected leaves provided straightforward results (Figure 3; Supplementary Table S4). Notably, JA was induced at an approximately 3-fold higher concentration at $48 \mathrm{~h}$ after Tramesan application on plants. SA was down-modulated both in the control (mock) and treated $(\mathrm{T})$ plants, the latter registering a lower decrease in SA compared to the mock plants. 


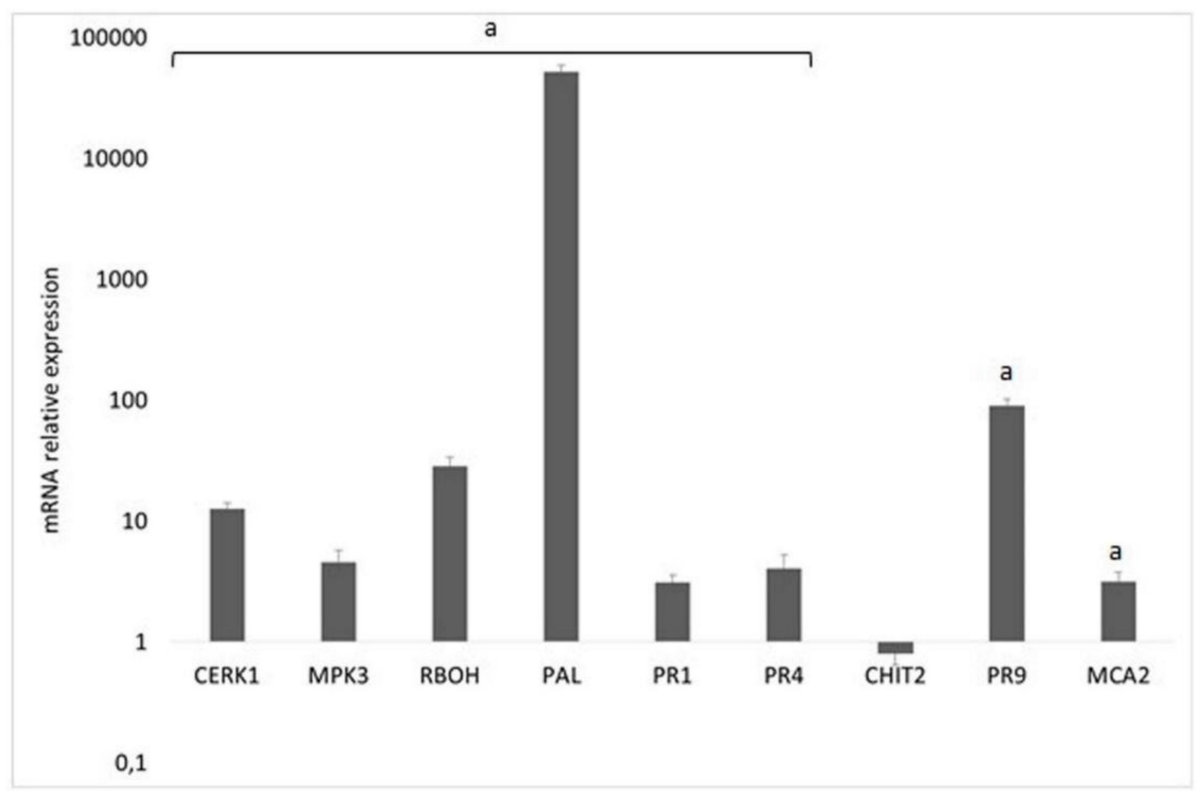

Figure 2. Expression profile of transcripts of genes CERK1, MPK3, NADPHox (RBOH), PAL, PR1, PR4, CHIT2, PR9, and MCA2 in durum wheat var. Svevo at $48 \mathrm{~h}$ after treatment with Tramesan $(3.3 \mu \mathrm{M})$. Expression is relative to values in untreated plants (control) and values represent the mean $\pm \mathrm{SE}$ as described in the Methods section. Small capital letters in the chart represent the significantly different groups ( $p<0.05 ;$ Fisher's test).

Recognition and signal transduction-related cerk1 and $m p k 3$ expressions were triggered by fungal infection and were even more enhanced in plants treated with Tramesan (Figure 4). Fungal infections depressed both SA and JA production at 24 hai (fold change (FC) in infected vs. non-infected samples: 0.15 for SA and 0.4 for JA). Pre-infection treatment with Tramesan ( $\mathrm{Tr}+\mathrm{Inf}$ ) had little effect on SA (FC of 0.25 for $\mathrm{Tr}+\mathrm{Inf}$ vs. non-infected control) but triggered JA biosynthesis (FC of 6.2 for $\mathrm{Tr}+\mathrm{Inf}$ vs. non-infected control) (Supplementary Table S2).

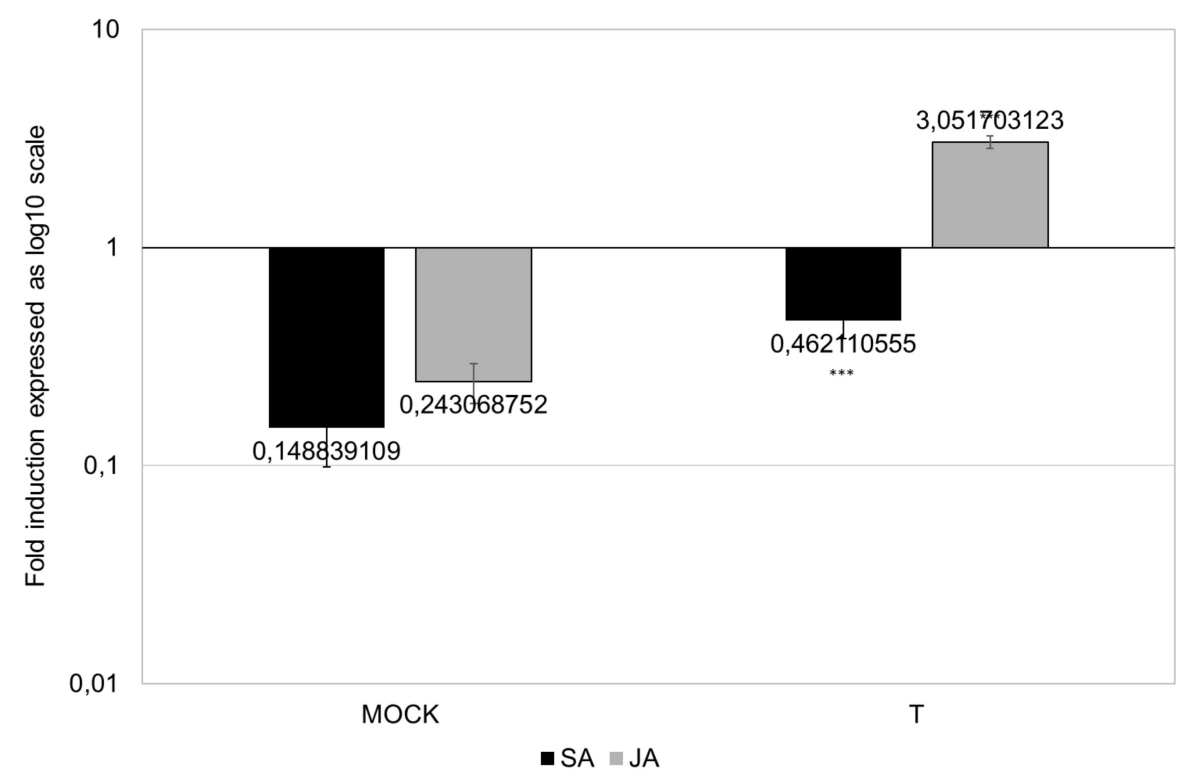

Figure 3. Fold induction (reported in $\log _{10}$ scale) of salicylic acid (SA) and jasmonic (JA) acid in durum wheat var. Svevo, after $48 \mathrm{~h}$ treatment $(\mathrm{T})$ or untreated (mock) with Tramesan $(3.3 \mu \mathrm{M})$. Values represent the mean $\pm \mathrm{SE}$ as described in the methods section. Small capital letters in the chart represent the significantly different groups ${ }^{* * *} p<0.001$; t-test). 

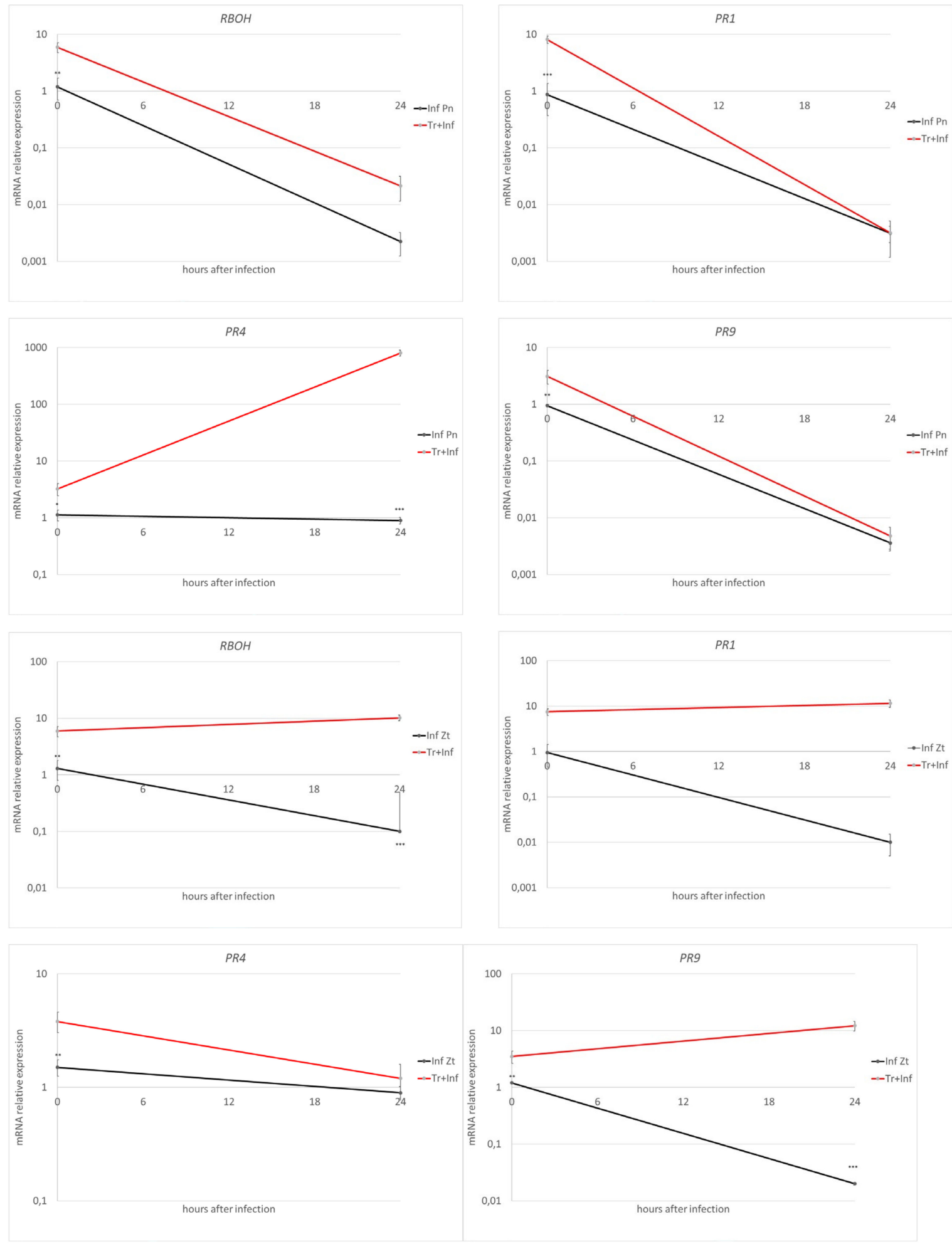

Figure 4. Expression profile of transcripts at 0 and 24 hours after infection (hai) of genes $R B O H, P R 1$, PR4, and PR9 in durum wheat var. Svevo infected with P. nodorum ST15465 (Inf Pn) or Z. tritici ST18258 (Inf $\mathrm{Zt})$ and infected with pathogens and pre-treated ( -48 hai) with Tramesan ( $\mathrm{Tr}+\mathrm{Inf})$. Expression is relative to values in untreated plants (CT-; without Tramesan, non-inoculated) and values represent the mean $\pm \mathrm{SE}$ as described in the methods section. Asterisks represent the significantly different values (* $p<0.05 ;{ }^{* *} p<0.01 ;{ }^{* * *} p<0.001 ;$ t-test). 
Potential indicators of plant response to damage, phenylalanine ammonia lyase $P A L$ that is the main hub for the phenylpropanoid pathway and metacaspase-encoding MCA2 that is active in the programmed cell death induced by biotic stress, were expressed at high levels even in the absence of the pathogen; while PAL did not change its expression profile after fungal infection (even though Tramesan strongly elicited its expression upon fungal infection), MCA2 was significantly upregulated after fungal inoculation (Supplementary Figures S2 and S3). P. nodorum infection down-regulated the expression of the respiratory burst oxidase $(R B O H)$; the product of this gene represents an indicator of stress response in plants. Similarly, Z. tritici infection pushed down $R B O H$ expression; only in this latter case did Tramesan aid its stimulation (Figure 4). This could be explained by the set of genes under the putative control of SA and JA, even when different outcomes were observed between the two pathogens. In fact, under P. nodorum infection, the expression of the SA-dependent pathway $P R 1$ and PR9 decreased in both treatments (Inf Pn and TR + Inf Pn), whereas the JA-modulated PR4 and Chit 2 showed an opposite trend: unaffected or slightly down-regulated in Inf Pn and strongly up-regulated in $\mathrm{Tr}+\operatorname{Inf} \mathrm{Pn}$ (Figure 4 and Supplementary Figure S2). On the contrary, Tramesan, in the presence of Z. tritici, up-regulated SA-dependent genes (e.g., PR1), whereas JA-controlled genes (e.g., PR4) were almost unaffected (Figure 4 and Supplementary Figure S3).

\section{Discussion}

Septoria Disease Complex is a major issue for European wheat farmers. Excessive cost of fungicides and the emerging fungicide resistance of pathogens are consistent threats to wheat yield. Even though several loci for resistance to SLBC were identified so far, a deficit in availability of resistant lines still remains [31]. One challenge in developing stable resistant lines might lie in the complexity of the SLBC disease. The two main effectors of this disease, Z. tritici and P. nodorum, play their pathogenic role in wheat differently. These differences emerge in the initial stage of infection: the hemibiotrophic $Z$. tritici avoids plant recognition by camouflaging its PAMP (e.g., chitin with Mg3LysM); the necrotrophic $P$. nodorum induces plant cell death via direct effects (e.g., ToxA vs. Tsn1 sensitivity gene) [10]. Nonetheless, twenty major $S t b$ genes providing a qualitative resistance to STB have been identified so far [32]. Therefore, it is reasonable to suppose that novel SLBC-resistant lines could be on the market within few years. Nowadays, the SLBC is becoming more and more of a constraint for wheat production worldwide since the emergence of Z. tritici and P. nodorum strains QI and SDHI-resistant [31].

The more and more restrictive country-based laws (e.g., EC/128/2009) confine the ability to eradicate the problem; moreover, in Europe, today the highest costs in wheat cultivation are those related to fungicides against SLBC. In view of this, the search for alternative products in limiting SLBC in wheat is gaining momentum $[29,30]$. In these studies, diverse natural elicitors (e.g., natural polysaccharides: $\lambda$-carragenan) can significantly limit SLBC in wheat (i.e., up to $70 \%$ under controlled growth conditions) by enhancing plant defenses exploiting both jasmonates and salicylate signaling pathways.

We show that Tramesan-a basidiomycete-derived exo-polysaccharide-could represent a natural, user-friendly, low-cost alternative to protect crops. Specifically, our results indicate that Tramesan supports wheat plants in controlling SLBC causal agents: P. nodorum and Z. tritici. However, Tramesan's mode of action is still an outstanding question.

We report that Tramesan is effective at augmenting the synthesis of defense-related hormones, notably JA, and of some markers of plant defenses (PR1 and PR4 inter alia). This effect occurs within 48 hours after Tramesan is applied, albeit not all the markers tested react linearly: the mitogen-activated protein MPK3 and the LysM receptor kinase CERK1 display high basal levels [31,32] even if induced by Tramesan and fungal infection. In contrast, $P A L, M C A 2$, and $R B O H$ are evidently controlled by additional inputs other than stress (ABA (-TAS14) and auxin (-PIN2)) [33,34]. The set of genes putatively regulated by SA, such as $P R 1$ and $P R 9$, or by JA, such as $P R 4[35,36]$, showed a straight correlation with the hormone levels. In the case of SA-controlled genes, NPR1 is the most likely mediator of the stimulus [37-41]. 
Based on our data, Tramesan elicits a high basal activation of plant defenses, even though the "nature" of this elicitation process remains to be determined. In this perspective, Tramesan can be envisioned as a MAMP that plants recognize as a non-self biomolecule to induce defense. The search for compounds, mainly microbe-derived, able to efficiently induce plant defenses is gaining momentum in the process of elucidating induced systemic resistance and defense priming patterns [14,16]. Our results did not allow assessment of whether Tramesan could induce an immune response (IR) or prime plant defenses; further studies are needed in this regard. Data could suggest that Tramesan is more than a "simple" MAMP: the onset of defense appears to be modulated over time, triggered by subsequent infection and effective at reducing pathogen growth and disease symptoms. Is it costly? Probably not: yield data from field experiments suggest that Tramesan did not affect durum wheat production. We hypothesize that Tramesan is recognized by specific receptors that, in turn, activate pathways leading to an antioxidant response in the host. Tramesan acts in several organisms (mammals, fungi, and plants) as an activator of antioxidant defenses [20]; when employed against mycotoxigenic fungi, it switches off aflatoxin synthesis-a process closely related to the antioxidant system of the cell-in Aspergillus section Flavi [42]. Therefore, along with inducing plant defenses, Tramesan can lower circulating reactive oxygen species (ROS) at the plant-pathogen interface, thus creating a less favorable environment for the necrotrophic growth of plant pathogens such as $P$. nodorum. Several receptors in various organisms are known to act as ligands of fungal glucans, and to trigger various responses (e.g., innate immunity to cell death or symbiosis [42-44]). Most recently, Gubaeva and colleagues proposed the "slipped sandwich" model for explaining the ability of AtCERK1 in bound and transduced oligochitosan (the most effective with a degree of polymerization up to 7-DP7) to induce defense reactions in A. thaliana [44]. Similar results were found in common wheat with the identification of receptor kinase proteins putatively able to bind oligochitosan [45].

In this context, we propose that Tramesan acts as a ligand for still unknown inter-kingdom conserved receptors, and that this recognition elicits host defenses to limit pathogen development and disease. The ability that Tramesan demonstrated in modulating cell antioxidation in other systems, along with the well-established relationship between plant defense onset and antioxidant modulation [45], suggest that the triggering of defense-related hormones and genes occurs at the very early steps following pathogen recognition.

Further studies in the field, under natural infection conditions, should allow us to better assess if the priming and memory effect of Tramesan in host plants does actually occur, and also its real effectiveness in controlling SLBC.

Supplementary Materials: The following are available online at http://www.mdpi.com/2218-273X/10/4/608/s1, Table S1: List of primers used within this study. Table S2: SNB severity (\%) on flag leaf at different days after Parastagonospora nodorum inoculation (dai) under field trials conditions. Table S3: averaged $2^{-\Delta \Delta C t}$ values \pm SE of the selected genes under treatment with solely Tramesan. Table S4: Average values (biological duplicate-technical triplicate) of relative abundance (normalized on NAA as ISTD) of salicylic and jasmonic acids in leaves of durum wheat var. Svevo, at different times (0-9 dai) pre- and post-inoculation with the pathogens P. nodorum (Inf Pn) or Z. tritici $(\operatorname{Inf} \mathrm{Zt})$ in wheat plants treated $(\mathrm{Tr}+\operatorname{Inf} \operatorname{Pn}$ and $\mathrm{Tr}+\operatorname{Inf} \mathrm{Zt})$ or not with $3.3 \mu \mathrm{M}$ Tramesan. Figure S1: Additional images of Svevo cultivar plots inoculated with Zymoseptoria tritici in field trials. Figure S2: averaged $2^{-\Delta \Delta \mathrm{Ct}}$ values $\pm \mathrm{SE}$ of the selected genes in Svevo treated or not with Tramesan and infected or not with P. nodorum. Figure S3: averaged $2^{-\Delta \Delta \mathrm{Ct}}$ values \pm SE of the selected genes in Svevo treated or not with Tramesan and infected or not with Z. tritici.

Author Contributions: Methodology, C.P., V.F., M.B., F.Q., M.F.; formal analysis, M.Z., B.M.; conceptualization, V.S.; investigation, V.S., C.P., S.Z., F.Q.; data curation, V.S., C.P., M.B., M.F., M.Z.; writing—original draft preparation, V.S., A.I. and M.R.; writing-review and editing, F.Q., M.Z., B.M., A.I.; visualization, M.R.; supervision, V.S., B.M., M.R, A.I.; validation, M.Z. and M.R.; funding acquisition, B.M., S.Z., M.R., A.I.; project administration, V.S. and M.R.; resources: S.Z., M.R., and A.I. All authors have read and agreed to the published version of the manuscript.

Funding: This research was supported by the Ministero dello Sviluppo Economico (MISE) through the POR FESR Horizon 2020 grant: "POSSIBILE” n. F/050019/03/X32. 
Acknowledgments: The authors wish to thank Piero Cacciatori for technical support in the field trials.

Conflicts of Interest: The authors declare no conflict of interest. The funders had no role in the design of the study or in the collection of data.

\section{References}

1. Quaedvlieg, W.; Verkley, G.J.M.; Shin, H.-D.; Barreto, R.W.; Alfenas, A.C.; Swart, W.J.; Groenewald, J.Z.; Crous, P.W. Sizing up septoria. Stud. Mycol. 2013, 75, 307-390. [CrossRef]

2. Bockus, W.W.; Bowden, R.L.; Hunger, R.M.; Murray, T.D.; Smiley, R.W. Compendium of Wheat Diseases and Pests; American Phytopathological Society (APS Press): St. Paul, MN, USA, 2010; ISBN 0890543852.

3. Fones, H.; Gurr, S. The impact of Septoria tritici Blotch disease on wheat: An EU perspective. Fungal Genet. Biol. 2015, 79, 3-7. [CrossRef] [PubMed]

4. Eyal, Z. The Septoria tritici and Stagonospora nodorum blotch diseases of wheat. Eur. J. Plant Pathol. 1999, 105, 629-641. [CrossRef]

5. Deslandes, L.; Rivas, S. Catch me if you can: Bacterial effectors and plant targets. Trends Plant Sci. 2012, 17, 644-655. [CrossRef] [PubMed]

6. Oliver, R.P.; Friesen, T.L.; Faris, J.D.; Solomon, P.S. Stagonospora nodorum: From pathology to genomics and host resistance. Annu. Rev. Phytopathol. 2012, 50, 23-43. [CrossRef]

7. Vincent, D.; Du Fall, L.A.; Livk, A.; Mathesius, U.; Lipscombe, R.J.; Oliver, R.P.; Friesen, T.L.; Solomon, P.S. A functional genomics approach to dissect the mode of action of the Stagonospora nodorum effector protein SnToxA in wheat. Mol. Plant Pathol. 2012, 13, 467-482. [CrossRef]

8. Linde, C.C.; Zhan, J.; McDonald, B.A. Population structure of Mycosphaerella graminicola: From lesions to continents. Phytopathology 2002, 92, 946-955. [CrossRef]

9. Kettles, G.J.; Kanyuka, K. Dissecting the molecular interactions between wheat and the fungal pathogen Zymoseptoria tritici. Front. Plant Sci. 2016, 7, 508. [CrossRef]

10. Duba, A.; Goriewa-Duba, K.; Wachowska, U. A review of the interactions between wheat and wheat pathogens: Zymoseptoria tritici, Fusarium spp. and Parastagonospora nodorum. Int. J. Mol. Sci. 2018, 19, 1138. [CrossRef]

11. Allioui, N.; Siah, A.; Brinis, L.; Reignault, P.; Halama, P. Identification of Qol fungicide-resistant genotypes of the wheat pathogen Zymoseptoria tritici in Algeria. Phytopathol. Mediterr. 2016, 89-97.

12. Parliament, E. Directive 2009/128/EC of the European Parliament and of the Council of 21 October 2009 establishing a framework for Community action to achieve the sustainable use of pesticides. Off. J. Eur. Union 2009, 309, 71-86.

13. Gupta, S.; Dikshit, A.K. Biopesticides: An ecofriendly approach for pest control. J. Biopestic. 2010, 3, 186.

14. Chalfoun, N.R.; Durman, S.B.; Budeguer, F.; Caro, M.d.P.; Bertani, R.P.; Di Peto, P.; Stenglein, S.A.; Filippone, M.P.; Moretti, E.R.; Díaz Ricci, J.C. Development of PSP1, a biostimulant based on the elicitor AsES for disease management in monocot and dicot crops. Front. Plant Sci. 2018, 9, 844. [CrossRef] [PubMed]

15. Mauch-Mani, B.; Baccelli, I.; Luna, E.; Flors, V. Defense priming: An adaptive part of induced resistance. Annu. Rev. Plant Biol. 2017, 68, 485-512. [CrossRef]

16. Hilker, M.; Schwachtje, J.; Baier, M.; Balazadeh, S.; Bäurle, I.; Geiselhardt, S.; Hincha, D.K.; Kunze, R.; Mueller-Roeber, B.; Rillig, M.C. Priming and memory of stress responses in organisms lacking a nervous system. Biol. Rev. 2016, 91, 1118-1133. [CrossRef]

17. Martinez-Medina, A.; Flors, V.; Heil, M.; Mauch-Mani, B.; Pieterse, C.M.J.; Pozo, M.J.; Ton, J.; van Dam, N.M.; Conrath, U. Recognizing plant defense priming. Trends Plant Sci. 2016, 21, 818-822. [CrossRef]

18. Helms, A.M.; De Moraes, C.M.; Tröger, A.; Alborn, H.T.; Francke, W.; Tooker, J.F.; Mescher, M.C. Identification of an insect-produced olfactory cue that primes plant defenses. Nat. Commun. 2017, 8, 1-9. [CrossRef]

19. Conrath, U.; Beckers, G.J.M.; Langenbach, C.J.G.; Jaskiewicz, M.R. Priming for enhanced defense. Annu. Rev. Phytopathol. 2015, 53. [CrossRef]

20. Scarpari, M.; Reverberi, M.; Parroni, A.; Scala, V.; Fanelli, C.; Pietricola, C.; Zjalic, S.; Maresca, V.; Tafuri, A.; Ricciardi, M.R. Tramesan, a novel polysaccharide from Trametes versicolor. Structural characterization and biological effects. PLOS ONE 2017, 12. [CrossRef] 
21. Zaccaria, M.; Ludovici, M.; Sanzani, S.M.; Ippolito, A.; Cigliano, R.A.; Sanseverino, W.; Scarpari, M.; Scala, V.; Fanelli, C.; Reverberi, M. Menadione-induced oxidative stress re-shapes the oxylipin profile of Aspergillus flavus and its lifestyle. Toxins 2015, 7, 4315-4329. [CrossRef]

22. Ricciardi, M.R.; Licchetta, R.; Mirabilii, S.; Scarpari, M.; Parroni, A.; Fabbri, A.A.; Cescutti, P.; Reverberi, M.; Fanelli, C.; Tafuri, A. Preclinical Antileukemia Activity of Tramesan: A Newly Identified Bioactive Fungal Metabolite. Oxid. Med. Cell. Longev. 2017, 2017. [CrossRef] [PubMed]

23. Agro-Food Microbial Culture Collection. Available online: http://server.ispa.cnr.it/ITEM/Collection/ (accessed on 14 April 2020).

24. Iori, A.; Scala, V.; Cesare, D.; Pinzari, F.; D’Egidio, M.G.; Fanelli, C.; Fabbri, A.A.; Reverberi, M.; Serranti, S. Hyperspectral and molecular analysis of Stagonospora nodorum blotch disease in durum wheat. Eur. J. Plant Pathol. 2015, 141, 689-702. [CrossRef]

25. Sameh, S.; Céline, R.-F.; Jean-Baptiste, A.; Boris, B. Accuracy of Real-time PCR to Study Mycosphaerella graminicola Epidemic in Wheat: From Spore Arrival to Fungicide Efficiency; InTechopen: London, UK, 2011.

26. CABI. Available online: https://www.cabi.org/services/microbial-services/culture-collection-microorganismsupply/ (accessed on 14 April 2020).

27. Liu, Z.H.; Friesen, T.L.; Rasmussen, J.B.; Ali, S.; Meinhardt, S.W.; Faris, J.D. Quantitative trait loci analysis and mapping of seedling resistance to Stagonospora nodorum leaf blotch in wheat. Phytopathology 2004, 94, 1061-1067. [CrossRef] [PubMed]

28. Nobili, C.; D’Angeli, S.; Altamura, M.M.; Scala, V.; Fabbri, A.A.; Reverberi, M.; Fanelli, C. ROS and 9-oxylipins are correlated with deoxynivalenol accumulation in the germinating caryopses of Triticum aestivum after Fusarium graminearum infection. Eur. J. Plant Pathol. 2014. [CrossRef]

29. Lee, W.-S.; Rudd, J.J.; Hammond-Kosack, K.E.; Kanyuka, K. Mycosphaerella graminicola LysM effector-mediated stealth pathogenesis subverts recognition through both CERK1 and CEBiP homologues in wheat. Mol. Plant Microbe Interact. 2014, 27, 236-243. [CrossRef]

30. Rudd, J.J.; Keon, J.; Hammond-Kosack, K.E. The wheat mitogen-activated protein kinases TaMPK3 and TaMPK6 are differentially regulated at multiple levels during compatible disease interactions with Mycosphaerella graminicola. Plant Physiol. 2008, 147, 802-815. [CrossRef]

31. O'Driscoll, A.; Kildea, S.; Doohan, F.; Spink, J.; Mullins, E. The wheat-Septoria conflict: A new front opening up? Trends Plant Sci. 2014, 19, 602-610. [CrossRef]

32. Arraiano, L.S.; Brown, J.K.M. Sources of resistance and susceptibility to Septoria tritici blotch of wheat. Mol. Plant Pathol. 2017, 18, 276-292. [CrossRef]

33. Ors, M.; Randoux, B.; Siah, A.; Couleaud, G.; Maumené, C.; Sahmer, K.; Reignault, P.; Halama, P.; Selim, S. A Plant Nutrient-and Microbial Protein-Based Resistance Inducer Elicits Wheat Cultivar-Dependent Resistance Against Zymoseptoria tritici. Phytopathology 2019, 109, 2033-2045. [CrossRef]

34. Le Mire, G.; Siah, A.; Marolleau, B.; Gaucher, M.; Maumené, C.; Brostaux, Y.; Massart, S.; Brisset, M.-N.; Jijakli, M.H. Evaluation of $\lambda$-Carrageenan, CpG-ODN, Glycine Betaine, Spirulina platensis, and Ergosterol as Elicitors for Control of Zymoseptoria tritici in Wheat. Phytopathology 2019, 109, 409-417. [CrossRef]

35. Beckers, G.J.M.; Jaskiewicz, M.; Liu, Y.; Underwood, W.R.; He, S.Y.; Zhang, S.; Conrath, U. Mitogen-activated protein kinases 3 and 6 are required for full priming of stress responses in Arabidopsis thaliana. Plant Cell 2009, 21, 944-953. [CrossRef] [PubMed]

36. Tateda, C.; Zhang, Z.; Shrestha, J.; Jelenska, J.; Chinchilla, D.; Greenberg, J.T. Salicylic acid regulates Arabidopsis microbial pattern receptor kinase levels and signaling. Plant Cell 2014, 26, 4171-4187. [CrossRef] [PubMed]

37. Zhang, Y.P.; Jiang, H.; Wang, L.; Zhou, J.; Zhu, D.F. A comparative study of stress-related gene expression under single stress and intercross stress in rice. Genet. Mol. Res. GMR 2015, 14, 3702-3717. [CrossRef] [PubMed]

38. Xia, X.-J.; Zhou, Y.-H.; Shi, K.; Zhou, J.; Foyer, C.H.; Yu, J.-Q. Interplay between reactive oxygen species and hormones in the control of plant development and stress tolerance. J. Exp. Bot. 2015, 66, 2839-2856. [CrossRef]

39. Rehrig, E.M.; Appel, H.M.; Jones, A.D.; Schultz, J.C. Roles for jasmonate-and ethylene-induced transcription factors in the ability of Arabidopsis to respond differentially to damage caused by two insect herbivores. Front. Plant Sci. 2014, 5, 407. [CrossRef] 
40. Rawat, S.; Ali, S.; Mittra, B.; Grover, A. Expression analysis of chitinase upon challenge inoculation to Alternaria wounding and defense inducers in Brassica juncea. Biotechnol. Rep. 2017, 13, 72-79. [CrossRef]

41. Miura, K.; Okamoto, H.; Okuma, E.; Shiba, H.; Kamada, H.; Hasegawa, P.M.; Murata, Y. SIZ1 deficiency causes reduced stomatal aperture and enhanced drought tolerance via controlling salicylic acid-induced accumulation of reactive oxygen species in A rabidopsis. Plant J. 2013, 73, 91-104. [CrossRef]

42. Reverberi, M.; Zjalic, S.; Ricelli, A.; Di Meo, C.; Scarpari, M.; Fanelli, C.; Fabbri, A. Mushrooms versus fungi: Natural compounds from Lentinula edodes inhibit aflatoxin biosynthesis by Aspergillus parasiticus. World Mycotoxin J. 2011, 4, 217-224. [CrossRef]

43. Limpens, E.; Franken, C.; Smit, P.; Willemse, J.; Bisseling, T.; Geurts, R. LysM domain receptor kinases regulating rhizobial Nod factor-induced infection. Science 2003, 302, 630-633. [CrossRef]

44. Gubaeva, E.; Gubaev, A.; Melcher, R.L.J.; Cord-Landwehr, S.; Singh, R.; El Gueddari, N.E.; Moerschbacher, B.M. 'Slipped sandwich'model for chitin and chitosan perception in Arabidopsis. Mol. Plant Microbe Interact. 2018, 31, 1145-1153. [CrossRef]

45. Shen, Q.; Liu, L.; Wang, L.; Wang, Q. Indole primes plant defense against necrotrophic fungal pathogen infection. PLoS ONE 2018, 13. [CrossRef] [PubMed]

(C) 2020 by the authors. Licensee MDPI, Basel, Switzerland. This article is an open access article distributed under the terms and conditions of the Creative Commons Attribution (CC BY) license (http://creativecommons.org/licenses/by/4.0/). 